\title{
Optimizing qPCR for the Quantification of Periodontal Pathogens in a Complex Plaque Biofilm
}

\author{
S.S. Kirakodu*, M. Govindaswami, M.J. Novak, J.L. Ebersole and K.F. Novak \\ Center for Oral Health Research, College of Dentistry, University of Kentucky College of Dentistry, Lexington, USA
}

\begin{abstract}
Quantitative PCR (qPCR) has recently been used to quantify microorganisms in complex communities, including dental plaque biofilms. However, there is variability in the qPCR protocols being used. This study was designed to evaluate the validity of two of these variables with the intent of developing a more standardized qPCR protocol. The two variables evaluated were (1) the use of DNA content versus actual cell counts to estimate bacterial numbers in mixed plaque samples and (2) the effectiveness of three different universal primers versus species specific primers in amplifying specific target pathogens in these samples. Results lead to the development of a standardized protocol that was shown to be highly reproducible as demonstrated by low coefficients of variation. The results also confirmed that this standardized qPCR protocol can be used as a sensitive method for quantifying specific bacterial species in human plaque samples.
\end{abstract}

Key Word: qPCR, oral bacteria, biofilms.

\section{INTRODUCTION}

Periodontitis is initiated by polymicrobial infections and characterized by inflammatory changes in the periodontal tissues leading to loss of periodontal ligament and alveolar bone [1]. It is widely accepted that the disease occurs as the result of an inflammatory response to a subgingival, bacterial biofilm, and is particularly related to an increase in Gramnegative anaerobes at the disease site [2]. Numerous reports have demonstrated a close association between periodontal tissue destruction and the development of a complex of microbial species within the biofilm that includes Porphyromonas gingivalis, Tannerella forsythia, Aggregatibacter (formerly Actinobacillus) actinomycetemcomitans, Treponema denticola, Prevotella intermedia, and Fusobacterium nucleatum [3-9].

Quantitative detection of these pathogens in clinical specimens has contributed to a better understanding of the crucial host-bacterial interactions that occur in periodontitis. In the past, cultivation methods have been considered the gold standard for describing the predominant microorganisms in dental biofilms $[5,10]$. Limitations of this method including difficulty in growing many of the fastidious microorganisms, inherent inaccuracy of counting methodologies, and high costs in terms of supplies and technical personnel, have pushed investigators to develop more sensitive, accurate, quantitative, and cost effective molecular techniques for enumerating bacteria in complex biofilms [5]. Approaches currently being used include DNA-DNA checkerboard hybridization [11,12], standard polymerase chain reaction (PCR) [13-15], and, more recently, real-time quantitative polymerase chain reaction (qPCR) [8,16-23]. The checkerboard hybridization technique routinely can detect $10^{4}$ cells but conditions can be altered to detect $10^{3}$ cells [24]. It is generally used to quantify ranges of bacteria

\footnotetext{
*Address correspondence to this author at the Center for Oral Health Research, 414 Health Sciences Research Building, 1095 VA Drive, University of Kentucky, Lexington, KY 40536-0305, USA; Tel: 859-323-0281; Fax: 859-257-6566; E-mail: sskira2@uky.edu
}

$\left(<10^{5}, 10^{5}-10^{6}\right.$ and $>10^{6}$ copies) [12]. Standard PCR lacks the ability for precise quantification since only an end-point determination can be analyzed. In contrast, qPCR provides precise counts through direct monitoring of the increasing amount of PCR product throughout the enzymatic assay. Thus, it appears that qPCR is the most sensitive of these available methods, with detection limits estimated at $10^{2}$ genome copies [25].

Initial evaluation of various reports using qPCR for the enumeration of oral bacteria revealed substantial variability in methodologies. These include variations in protocols used to generate the standard curves for $\mathrm{qPCR}$ and differences in the universal primer sets used to amplify $16 \mathrm{~S}$ rDNA $[8,16$, $17,19,20,22,23,26]$. There are no reports in the literature that evaluate and compare how these different methodologies affect the outcomes of bacterial quantification. Given that qPCR is becoming an accepted technology for the quantitative analysis of bacteria from mixed biofilm samples, this study was designed to compare these variables with the intent of developing a more standardized qPCR protocol. Specifically, the aims of this study were: (i) to compare the use of actual cell counts versus a standard formula based on total DNA to estimate the total number of bacteria present in bacterial cultures that are being used to generate qPCR standard curves; (ii) to determine the effectiveness of three different universal primer sequences versus species specific primers in amplifying $16 \mathrm{~S}$ rDNA obtained from cultures of the seven target bacteria; (iii) to determine the reproducibility of qPCR using LightCycler technology in amplifying total bacteria and seven individual bacteria, and, (iv) to use a standardized qPCR procedure to quantify the total bacterial load in samples of oral biofilms, and the numbers of the seven target periodontal bacteria in the complex microbial samples.

\section{MATERIALS AND METHODS}

\section{Bacterial Strains and Growth Conditions}

Bacterial strains used in this study were purchased from ATCC (ATCC, Rockville, MD) and cultured in a Coy an- 
aerobic chamber in an atmosphere of $85 \% \mathrm{~N}_{2}, 5 \% \mathrm{CO}_{2}$ and $10 \% \mathrm{H}_{2}$ at $37^{\circ} \mathrm{C}$. F. nucleatum ATCC 25586 and A. actinomycetemcomitans ATCC 700685 were cultured in 3\% Trypticase Soy broth supplemented with $0.6 \%$ yeast extract. $P$. gingivalis ATCC BAA-308 and P. intermedia ATCC 25611 were cultured in $2.1 \%$ Mycoplasma broth supplemented with $0.5 \%$ hemin and $0.1 \%$ menadione. T. denticola ATCC 35405 was cultured in GM-1 broth [27]. T. forsythia ATCC 43037 was cultured in $4 \%$ Tryptic Soy broth supplemented with $0.5 \%$ hemin and $0.001 \% \mathrm{~N}$-acetylmuramic acid. Campylobacter rectus ATCC 33238 was cultured in 2\% Mycoplasma broth supplemented with $0.2 \%$ ammonium formate, $0.3 \%$ disodium fumarate, $0.5 \%$ hemin, $\mathrm{pH}$ adjusted to 7.3 and $2 \%$ horse serum (not heat inactivated). All growth media were pre-reduced in the anaerobic chamber for 24-36 hrs prior to inoculation with bacteria. Following growth to latelog phase an aliquot from each culture was removed, diluted 10 -fold, and used to estimate the total bacterial count (Petroff-Hausser counter). Each culture was also Gram stained to check for purity and cell morphology. Duplicate, $1 \mathrm{ml}$ aliquots of each culture were dispensed in eppendorf tubes and the cells pelleted by centrifugation at $10,000 \mathrm{~g}$ for $10 \mathrm{~min}$ using a microcentrifuge. The spent medium was discarded, leaving $25 \mu \mathrm{l}$ for resuspension of the cell pellet. These aliquots, containing a known number of bacteria, were then stored at $-80^{\circ} \mathrm{C}$ until they were used for DNA isolation and generation of standard curves for qPCR.

\section{Collection and Storage of Bacterial Plaque Samples}

After obtaining appropriate institutional review board approval, two individual human subgingival bacterial plaque samples were collected at least four months apart from five patients with periodontitis (defined as the presence of 4 or more teeth with a probing depth of at least $4 \mathrm{~mm}$ and clinical attachment loss of at least $2 \mathrm{~mm}$, and bleeding on probing at $35 \%$ or more of tooth sites). Samples were taken from the four deepest sites of the dentition that bled on probing and were pooled into sterile phosphate buffered saline (PBS, $\mathrm{pH}$ 7.2). The samples were stored at $-80^{\circ} \mathrm{C}$ until processed for qPCR.

\section{DNA Isolation}

DNA was isolated from the frozen, pure cultures of each individual target bacterium using the Masterpure ${ }^{\mathrm{TM}}$ kit from Epicenter (Epicenter, Madison WI) and quantified by LightCycler green dye (Idaho Technologies) using the LightCycler 2.0 instrument (Roche Applied Science).

Bacterial plaque samples in sterile PBS were centrifuged at $10,000 \mathrm{~g}$ to pellet the bacterial cells. DNA was extracted from the pelleted cells using the Masterpure ${ }^{\mathrm{TM}}$ kit and quantified as described above. DNA from each sample was resuspended in $100 \mu \mathrm{l}$ of sterile water.

\section{Comparing Actual Cell Counts to Determination by a Standard Formula}

The generation of standard curves for the enumeration of test bacteria is an essential component of qPCR. Two methods are generally used to accomplish this - actual cell counting or calculation based on a standard formula. To compare these two methods, the seven bacterial strains were grown in pure culture to late log phase, actual cell counts evaluated using a Petroff-Hausser counting chamber, and DNA isolated. The cell counts for each test organism were then compared with the estimated number of copies of each microorganism in the isolated DNA using the following formula: (Avogadro constant $X$ amount of DNA in $\mu \mathrm{g} / \mu \mathrm{l}$ ) / (genome size $\mathrm{X} \mathrm{mw}$ ), where $\mathrm{mw}$ is the molecular weight per base pair or nucleotide which is $660 \mathrm{Da}[28,29]$.

\section{Quantitative (Real-Time) Polymerase Chain Reaction}

Real-time PCR was performed using a LightCycler 2.0. Each PCR was performed in a total volume of $20 \mu 1$ containing $2 \mu \mathrm{l}$ of 10X LightCycler FastStart DNA Master SYBR Green I, $0.5 \mu \mathrm{M}$ each of HPLC purified forward and reverse primers (Table 1), $4 \mathrm{mM} \mathrm{MgCl}_{2}$ and $1 \mu \mathrm{l}$ of template DNA. Real-time PCR was carried out with an initial incubation of $10 \mathrm{~min}$ at $95^{\circ} \mathrm{C}$ followed by 45 cycles consisting of denaturing at $95^{\circ} \mathrm{C}$ for $10 \mathrm{sec}$; annealing (for annealing temperature see Table 1) for $5 \mathrm{sec}$ followed by amplification at $72^{\circ} \mathrm{C}$ for $\mathrm{X}$ sec, where $\mathrm{X}$ is the amplification time in seconds (product size/25). At the end of each cycle, fluorescent products were detected by the LightCycler 2.0. After amplification, a melting curve analysis was performed to determine the specificity of the PCR products. For melting curve analysis PCR products were incubated for $15 \mathrm{sec}$ at $5^{\circ} \mathrm{C}$ below the annealing temperature for the respective primers and the temperature was increased to $95^{\circ} \mathrm{C}$ with a ramp rate of $0.1 / \mathrm{sec}$. DNA strands separate or melt depending on the sequences, the length of the strand and the GC content of the strand. Because melting temperatures vary according to these differences, melting temperature profiles were used to identify and genotype the PCR products.

Quantification analysis was performed using LightCycler 4.0 software. Quantification analysis uses sample "crossing points" (CP) to determine the presence and the concentration of the target DNA in known and unknown samples after amplification. The quantification module only considers fluorescence values measured in the exponentially growing phase of the PCR amplification process. Standard curves were generated for all the target bacteria using DNA from pure cultures and species specific DNA primers. DNA isolated from a pure culture of $P$. gingivalis was used in generating a standard curve for the universal primers [3,26]. Ten fold serial dilutions of genomic DNA (DNA from $10^{7}, 10^{6}$, $10^{5}, 10^{4}, 10^{3}, 10^{2}$ and $10^{1}$ cells), from pure bacterial cultures provided seven data points for standard curve generation. In each standard curve, the concentration of standard sample (known amount of DNA/DNA from known number of bacteria) was plotted against its crossing points. Quantification of the individual target bacteria and total bacteria from the experimental samples were calculated using the standard curves.

\section{RESULTS}

\section{Comparison of Actual Cell Counts to Estimation by Standard Formula}

Results of experiments designed to compare the use of actual cell counts versus a theoretical formula in estimating the total number of bacteria present in pure cultures for development of standard curves revealed that in every case, estimated counts were higher based on use of the formula than those obtained from actual microscopic counts (Table 
Table 1. 16S rDNA Bacterial Primers and Annealing Temperatures Used in Real Time PCR and Expected Product Size

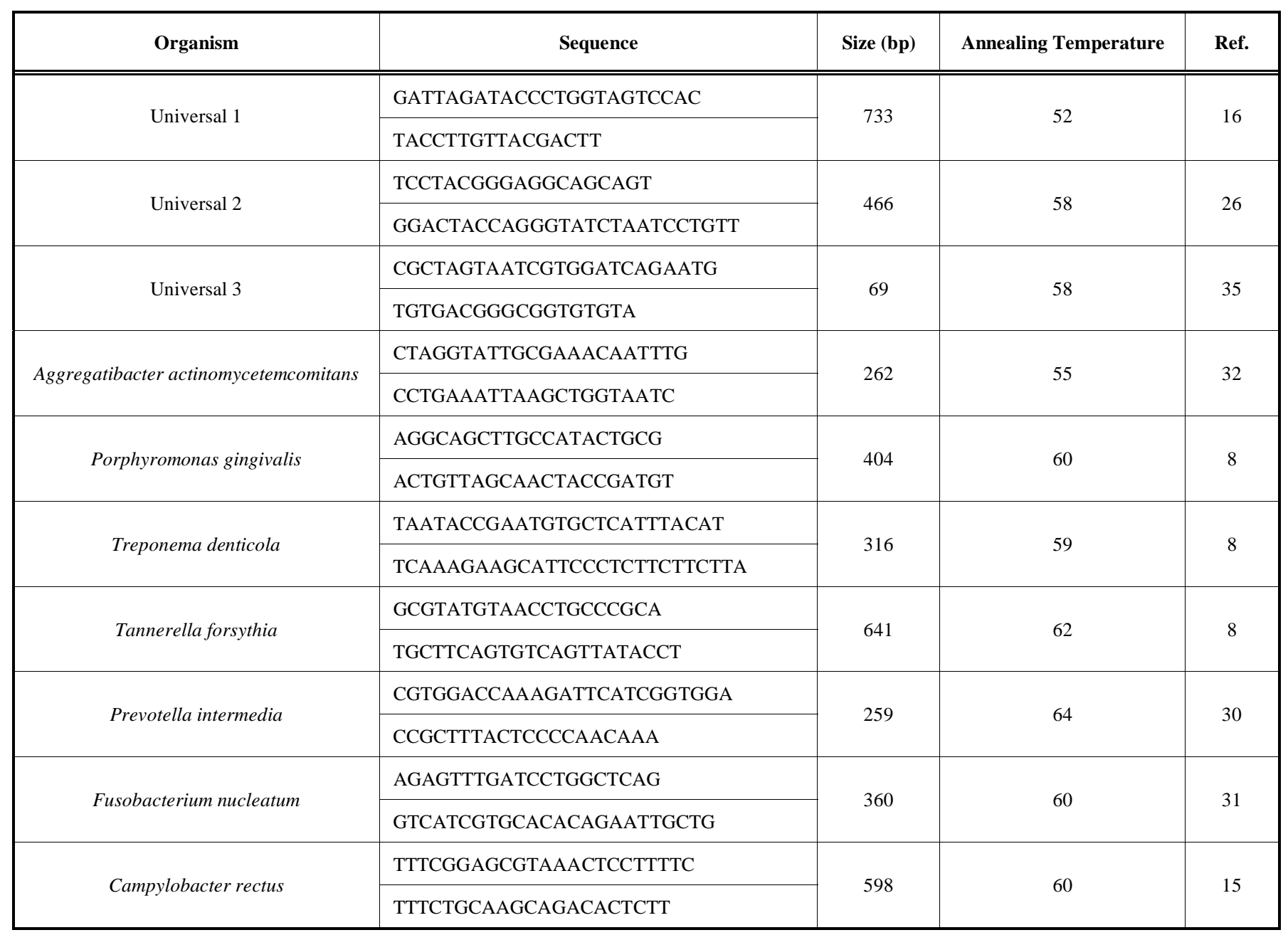

2). Results using the two methods were most similar for $T$. forsythia and $P$. gingivalis although both methods yielded results in the same log value. It should be noted that the species with the greatest percentage deviation, C. rectus, required an estimation of genome size based upon the average genome sizes for sequenced Campylobacter species (Campylobacter jejuni RM1221 and Campylobacter jejuni subsp. jejuni NCTC 11168; http://www.ncbi.nlm.nih.gov/genomes/ lproks.cgi).

\section{Comparing the Effectiveness of Different Universal Primers}

Crossing point (CP) values were used to evaluate the effectiveness of three different, published, universal primer sequences in amplifying DNA obtained from pure cultures of the seven target periodontal microorganisms by comparing them with species specific primers. These species specific primers were specifically selected from published articles and have been validated and used extensively in amplifying oral bacteria from plaque samples [8, 15, 30,31,32].

Results from these experiments revealed that Universal primer set 1 (Table 1) consistently yielded CP values most closely aligned with the species-specific primers across all seven target species (Table 3). Universal primer set 2 yielded
$\mathrm{CP}$ values that were lower than that of Universal primer set 1 for all species except $T$. denticola. In general, Universal primer set 3 did not perform well, yielding $\mathrm{CP}$ values that were significantly higher than those obtained with the species-specific primers. One exception was A. actinomycetemcomitans for which the $\mathrm{CP}$ value was lower than that found with the species-specific primer.

\section{Reproducibility of qPCR}

Reproducibility of the qPCR for the assessment of total microbial counts as well as counts of each of the seven target species of bacteria was determined using 22 individual plaque samples. Each sample, with each primer set, was evaluated in triplicate. The coefficient of variation $(\mathrm{CV})$ for each sample was calculated and the median for the 22 samples was determined. The results showed a $6.9 \%$ median for the Universal primer and the median $\mathrm{CV}$ for the seven bacteria ranged from $4.8 \%$ to $10.4 \%$ (Table 4 ). Thus, the qPCR quantification was very reproducible regardless of the characteristics of the individual plaque samples. Additionally, we determined if there was a relationship between the $\mathrm{CV}$ and the number of any particular bacterial species in the sample. The results showed no significant correlation for the $\mathrm{CV}$, irrespective of whether the sample had high or low levels of a particular species. 
Table 2. Comparison of Actual Cell Counts Versus a Standard Formula* in Estimating Total Bacteria Present in Pure Cultures

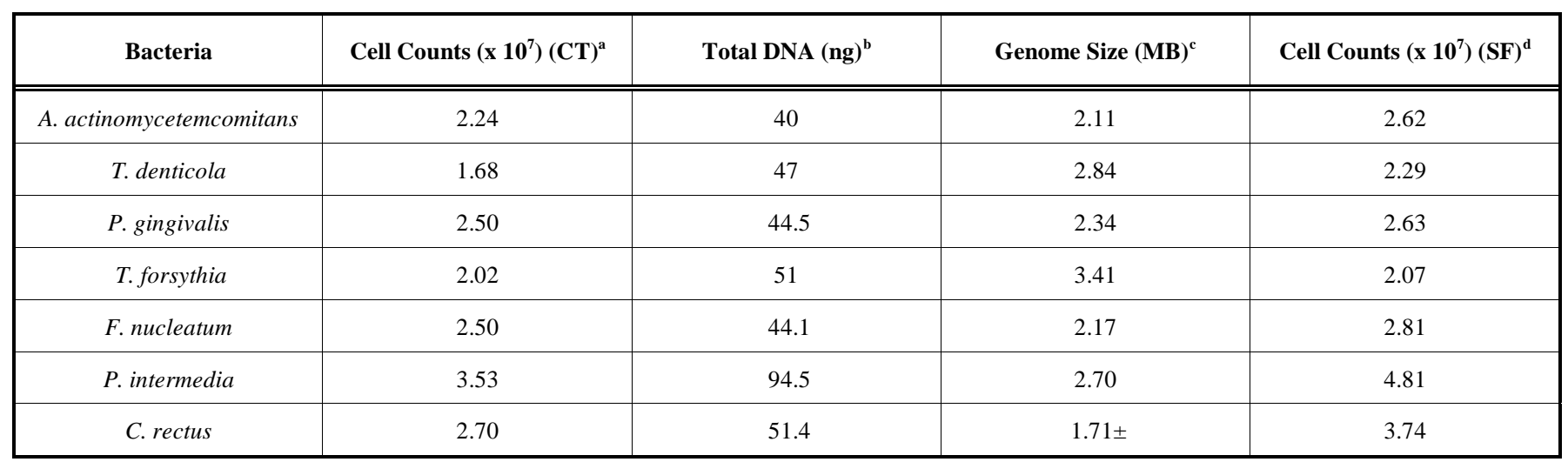

*Standard formula: (Avogadro constant X amount of DNA in $\mu \mathrm{g} / \mu \mathrm{l}$ ) / (genome size $\mathrm{X} \mathrm{mw}$ ), where mw is the molecular weight per base pairs or nucleotide which is $660 \mathrm{Da}$ ); a: actual microscopic bacterial counts using a Petroff-Hausser counting chamber; b: total DNA isolated from each bacterial culture; c: Genome size based on published genome sequence for each oral bacterial species; \pm : estimated genome size based on published genome sequences for Campylobacter jejuni RM1221 and Campylobacter jejuni subsp. jejuni NCTC 11168 (http://www.ncbi.nlm.nih.gov/genomes/lproks.cgi); d: calculated cell numbers using the standard formula (SF; 5,11).

Table 3. Crossing Point Values Using Species Specific and Universal Primers

\begin{tabular}{|c|c|c|c|c|c|}
\hline Species & DNA (ng) & Species Specific Primer & Universal Primer 1 & Universal Primer 2 & Universal Primer 3 \\
\hline \hline A. actinomycetemcomitans & 2 & 15.6 & 12.62 & 10.76 & 11.27 \\
\hline P. gingivalis & 2 & 13.5 & 14.06 & 18.75 & 13.06 \\
\hline T. denticola & 2 & 14.05 & 13.82 & 11.04 & 28.46 \\
\hline T. forsythia & 2 & 14.49 & 14.56 & 12.46 & 17.28 \\
\hline F. nucleatum & 2 & 12.53 & 14.61 & 10.98 & 24.79 \\
\hline P. intermedia & 2 & 14.05 & 13.88 & 19.98 \\
\hline C. rectus & 2 & 14.64 & & 13 \\
\hline
\end{tabular}

Table 4. The Coefficient of Variation (CV) from qPCR Runs for Different Primer Sets

\begin{tabular}{|c|c|c|c|c|c|c|c|c|}
\hline & Universal & $A a^{*}$ & $P g$ & $T f$ & $F n$ & $P i$ & $\mathrm{Cr}$ & $T d$ \\
\hline Mean CV & $9.25 \%$ & $7.92 \%$ & $10.04 \%$ & $9.00 \%$ & $10.35 \%$ & $12.24 \%$ & $8.70 \%$ & $7.22 \%$ \\
\hline Median CV & $6.94 \%$ & $6.88 \%$ & $10.42 \%$ & $7.72 \%$ & $6.51 \%$ & $6.19 \%$ & $6.27 \%$ & $4.79 \%$ \\
\hline Correl & -0.1067 & 0.2178 & -0.3243 & -0.0846 & -0.2952 & -0.1470 & -0.1651 & -0.3712 \\
\hline
\end{tabular}

*Aggregatibacter actinomycetemcomitans (Aa); Porphyromonas gingivalis (Pg), Tannerella forsythia (Tf); Fusobacterium nucleatum (Fn); Prevotella intermedia (Pi); Campylobacter rectus $(\mathrm{Cr})$; Treponema denticola $(\mathrm{Td})$.

Mean denotes mean CV\% from 22 samples tested in triplicate for all primers except $A a$, which was derived from the 12 samples that contained measureable $A a$. Median denotes the median CV\% for the same samples. Correl denotes the rank correlation of the CV\% with the total number of bacteria (Universal) or the number of the individual species. A minimum correlation coefficient of \pm 0.4227 is required for a $p<0.05$ level of significance.

\section{Enumeration of Bacterial Species in a Complex Biofilm}

Using the standardized protocol described above we quantified both total bacteria and individual counts of the seven target microorganisms in 10 individual mixed plaque biofilm samples (Table 5). Total bacteria and specific bacteria from the plaque samples were enumerated by using the standard curves generated from the actual bacterial cell counts. After factoring in the total volume of each sample, we determined that the total bacterial load in all samples, except sample 7 , averaged $3.97 \times 10^{8}$ cells. Total bacterial load in sample 7 was a full log higher, at 1.07 X $10^{9}$ cells. In contrast, counts of the seven specific bacteria where highly variable among the samples. This variability was most notable in A. actinomycetemcomitans, where counts ranged from undetectable (samples 1, 2, 5 and 6) to $7.97 \times 10^{6}$. This highest value was found in sample 7 , which also had the highest total bacterial count. Levels of $P$. gingivalis also were highly variable, ranging from $6.1 \times 10^{2}$ (sample 2) to $8.67 \times 10^{7}$ (sample 7). There was less variability among 
Table 5. qPCR Enumeration of Total Bacteria and Specific Bacterial Species in $100 \mu$ l of Plaque DNA

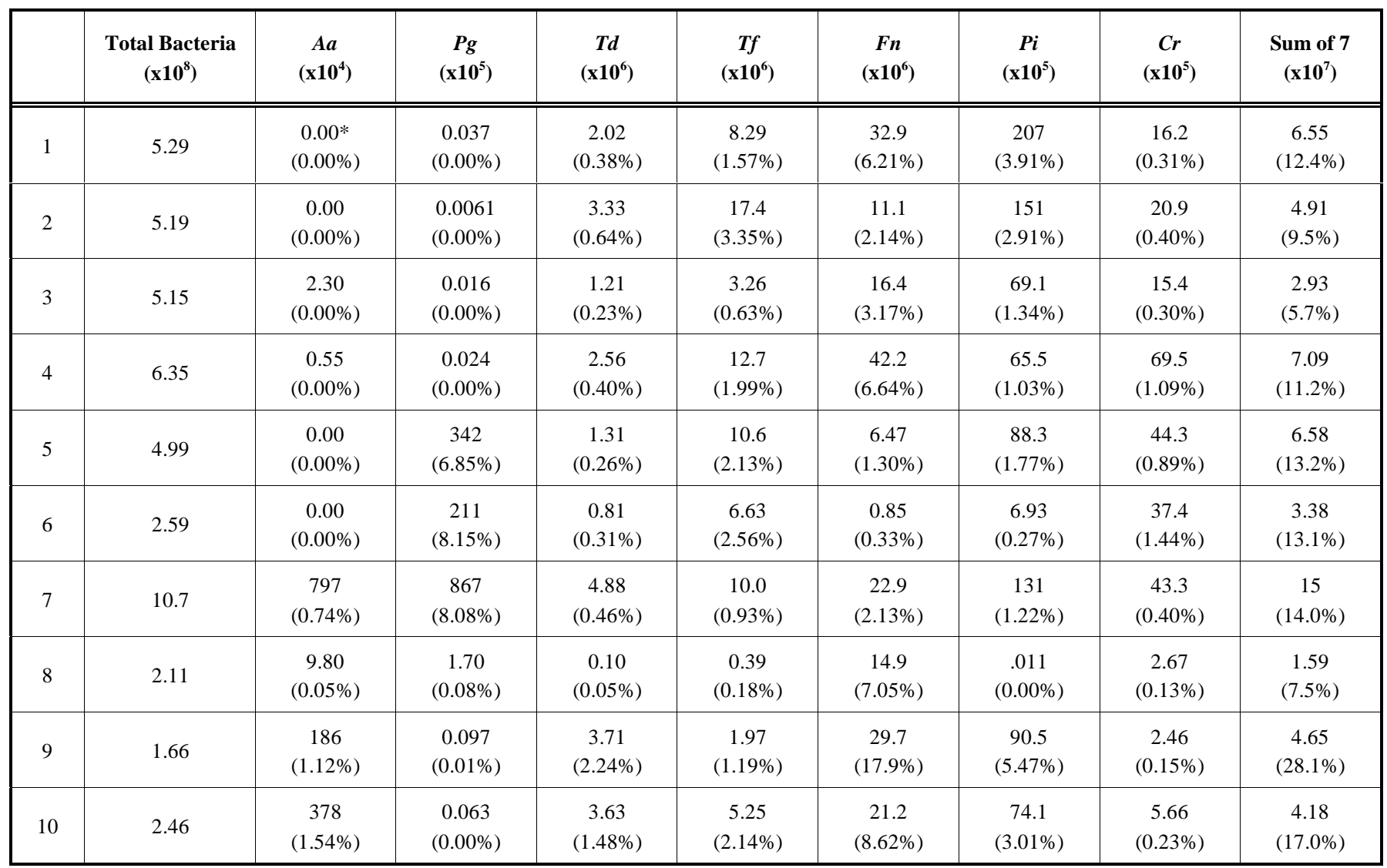

*Values are expressed as absolute counts and percentage of total bacteria (in parentheses), Universal primer 1 was used for enumeration of total bacteria and species-specific primers for A. actinomycetemcomitans $(A a), P$. gingivalis $(P g)$, T. denticola $(T d)$, . forsythia $(T f), F$. nucleatum $(F n), P$. intermedia $(P i)$ and $C$. rectus $(C r)$.

counts of other species, with all samples remaining within one $\log$ of each other. The sum of all seven target microorganisms averaged $4.65 \times 10^{7}$ in the ten samples. Sample 7 had higher total counts of these seven bacteria, with a total of $1.50 \times 10^{8}$. The data also were expressed as the percentages of these seven species in the total mixed plaque samples. These ranged from $0 \%$ (A. actinomycetemcomitans and $P$. gingivalis) to $8.6 \%$ ( $F$. nucleatum). Assessment of the sum of all seven as a percentage of total counts revealed that these specific microorganisms comprised $7.5 \%-28.1 \%$ of the total microbial flora.

\section{DISCUSSION}

This study focused on details of a reproducible methodology to utilize modern qPCR technology to quantify the numbers and distribution of individual bacterial species within a complex microbial ecology. In addition to the differences in methodology described above, there are different systems available for carrying out qPCR reactions. For example, both TaqMan probes and SYBR Green have been used in qPCR for quantification and identification of oral bacteria. Maeda et al. [33] have reported that there are no significant differences between the TaqMan and SYBR Green chemistry in their specificity and sensitivity. However, the SYBR Green assay involves fewer manipulations than the TaqMan assay and therefore appears to be the less complex of the two. We therefore chose to use the SYBR
Green technology in the LightCycler 2.0 system in this study.

A unique feature of this study was to compare the use of actual bacterial cell counts to the use of a standard formula to estimate the total number of a particular bacterial species present in a microbial sample. Kuboniwa et al. [34] reported that the yield of purified genomic DNA from pure cultures of $P$. gingivalis, where the cell number had been determined by colony counting, was considerably less than the calculated genomic weight. This suggested that, as one might anticipate, estimating total bacterial counts by cell counts may not be suitable to provide accurate enumeration of bacterial numbers in samples. However, both methods have been used in the development of standard curves for qPCR [5,7,33,35], thus, a more detailed comparison was desirable to evaluate validity/accuracy of these methods. The results demonstrated that, with the seven oral bacteria used in this study, differences were routinely noted between the two methods, with absolute counts being consistently lower than those obtained with the standard formula. However, the magnitude of these differences may not be significant given that in all cases, the $\log$ values of the counts were identical using either method (Table 2). Given the technical limitations in microscopic counting and the likely differences in absolute genome size between bacterial strains used in various studies versus the genome sequencing strains, 20\% variability between the methods would be expected to be within the margin of error. 
Moreover, in clinical applications, these techniques will be used to assess differences in counts of periodontal microorganisms either longitudinally within the same patients or in cross-sectional designs between groups of individuals. Consequently, log-fold changes would generally be considered the basis for describing changes over time in patients and/or among groups. This magnitude of change is consistent with other methodologies designed to assess differences in microbial counts in clinical studies. Therefore, our data suggests that either method can be used to assess the total numbers of individual bacterial species within a complex sample. In those cases where the genome size may not be available for the bacterium of interest, eg. C. rectus, absolute bacterial counts may provide the optimal method.

Each of the universal primer sets used in this study has been used in qPCR analysis of human bacterial samples $[16,26,35]$. Universal Primer 1 has been used in studies of oral treponemes and $P$. gingivalis [16]. Nadakarni et.al; [19] used Universal Primer 2 and compared its efficiency in amplifying DNA from 34 species of bacteria. They reported that the anaerobic bacteria estimated by this universal primer set in carious dentine was 40 -fold greater than the total bacterial load detected by culture methods, demonstrating the utility of real-time PCR. Finally, Universal Primer 3 has been reported as a useful tool in studies of a rapid method for the quantification $A$. actinomycetemcomitans and $P$. gingivalis in saliva and subgingival plaque [23]. However, this is the first individual study to evaluate the effectiveness of these different universal primers, as compared with species specific primers, to amplify $16 \mathrm{~S}$ rDNA from oral bacteria. The results clearly showed variability in the consistency of different primer sets to accurately estimate individual bacteria that would be components of complex oral microbial samples. An extreme example was Universal primer 3 which demonstrated exceptionally variable $\mathrm{CP}$ values across the 7 oral bacteria when compared to the species-specific primers. However, it must be noted that Universal primer 3 was originally designed for use in TaqMan probe analysis and its small amplicon size may not be suitable for the SYBR method used in this study. As importantly, we determined that Universal primer 1 provided consistent CP values compared to the specific primer sets for these seven oral bacteria.

Reproducibility of qPCR reactions and methodology and the need to provide replicate sample analyses may be of concern when evaluating large numbers of samples from multiple patients. In an evaluation, universal and species specific primers were tested by triplicate qPCR runs for 22 plaque samples and we demonstrated that $\mathrm{qPCR}$ is highly reproducible (Table 4). These results are in accordance with the published reports of Betzl et al. [36] and indicate that replicate qPCR runs are not necessary to accurately assess microbial populations in mixed bacterial samples.

Using the standardized methods described in this study, we applied a qPCR approach towards quantifying the seven target bacteria in human subgingival biofilm samples from patients with periodontitis (Table 5). Total bacteria in the plaque sample were enumerated using universal primer 1 and individual bacterial counts using the species specific primers (Table 1). As expected, there were differences between samples in individual bacterial counts and the individual proportions of each species within the samples. These differences are reflective of the inherent variability in the microbial ecology among individuals. However, because samples were obtained from periodontitis sites, it was anticipated that one or more of the target pathogens would be present in each sample. The results demonstrated that all of the test samples harbored a minimum of five of these pathogens. In addition, the sum of the target bacteria represented a consistent proportion of the total plaque sample ranging from $5 \%$ to $28 \%$. All of these results are consistent with previous studies showing that periodontal pockets typically harbor these bacteria within the ranges found in our study [37]. The general overall agreement in the distribution and quantities of the bacteria supported the validity and utility of this qPCR approach for evaluating microbial species and changes in subgingival biofilm samples as a function of disease progression or interventional therapy.

\section{ACKNOWLEDGEMENTS}

This work was supported by U01 AG021406 from the National Institute on Aging and U01 DE014338 from the National Institute for Dental and Craniofacial Research.

\section{REFERENCES}

[1] Novak MJ. In: Newman MG, Takei HH, Carranza FA, Ed. Clinical Periodontology 9th ed. Saunders WB, Philadelphia, PA, 2002; 6473

[2] Haake SK, Newman MG, Nisengard RJ, Sanz M. In: Newman MG, Takei HH, Carranza FA Ed. Clinical Periodontology 9th ed. Saunders WB, Philadelphia, PA, 2002; 96-112.

[3] Doungudomdacha S, Rawlinson A, Douglas CW. Enumeration of Porphyromonas gingivalis, Prevotella intermedia and Actinobacillus actinomycetemcomitans in subgingival plaque samples by a quantitative-competitive PCR method. J Med Microbiol 2000; 49: 861-74.

[4] Griffen A.L, Becker MR, Lyons SR. Prevalence of Porphyromonas gingivalis and periodontal health status. J Clin Microbiol 1998; 36 3239-42.

[5] Loomer PM. Microbiological diagnostic testing in the treatment of periodontal diseases. Periodontol 2000 2004; 34: 49-56.

[6] Nonnenmacher C, Dalpke A, Mutters R, Heeg K. Quantitative detection of periodontopathogens by real-time PCR. J Microbiol Methods 2004; 59: 117-25.

[7] Sakamoto M., Huang Y, Ohnishi M, Umeda M, Ishikawa I, Benno Y. Changes in oral microbial profiles after periodontal treatment as determined by molecular analysis of $16 \mathrm{~S}$ rRNA genes. J Med Microbiol 2004; 53: 563-71.

[8] Sakamoto M, Takeuchi Y, Umeda M, Ishikawa I, Benno Y. Rapid detection and quantification of five periodontopathic bacteria by real-time PCR. Microbiol Immunol 2001; 45(1): 39-44.

[9] Slots J, Ting M. Actinobacillus actinomycetemcomitans and Porphyromonas gingivalis in human periodontal disease: occurrence and treatment. Periodontol 2000; 20: 82-121.

[10] Dzink JL, Socransky SS, Haffajee AD. The predominant cultivable microbiota of active and inactive lesions of destructive periodontal diseases. J Clin Periodontol 1998; 15: 316-23.

[11] Conrads G, Mutters R, Fischer J, Brauner A, Lutticken R, Lampert F. PCR reaction and dot-blot hybridization to monitor the distribution of oral pathogens within plaque samples of periodontally healthy individuals. J Periodontol 1996; 67: 994-1003.

[12] Socransky SS, Smith C, Martin L, Paster BJ, Dewhirst FE, Lewin AE. "Checkerboard" DNA-DNA hybridizations. Biotechniques 1994; 17: 788-92.

[13] Ashimoto A, Chen C, Bakker I, Slots J. Polymerase chain reaction detection of 8 putative periodontal pathogens in subgingival plaque of gingivitis and advanced periodontitis lesions. Oral Microbiol Immunol 1996; 11: 266-73.

[14] Meurman JH, Wahlfors J, Korhonen A, Alakuijala P, Vaisanen P, Torkko H, Janne J. Identification of Bacteriodes forsythus in subgingival dental plaque with the aid of a rapid PCR method. J Dent Res 1997; 76: 1376-80. 
[15] Slots J, Ashimoto A, Flynn MJ, Li G, Chen C. Detection of putative periodontal pathogens in subgingival specimens by $16 \mathrm{~S}$ ribosomal DNA amplification with the polymerase chain reaction. Clin Infect Dis 1995; 20(suppl 2): S304-7.

[16] Asai Y, Gino T, Igarashi H, Ohyama Y, Ogawa T. Detection and quantification of oral treponemes in subgingival plaque by realtime PCR. J Clin Microbiol 2002; 40(9): 3334-40.

[17] Lyons SR, Griffen AL, Leys EJ. Quantitative real-time PCR for Porphyromonas gingivalis and total bacteria. J Clin Microbiol 2000; 38: 2362-5.

[18] Morillo JM, Lau L, Sanz M, Herrera D, Martin CM, Silva A. Quantitative real-time polumerase chain reaction based on single copy gene sequence for detection of periodontal pathogens. J Clin Periodontol 2004; 31: 1054-60.

[19] Nadkarni MA, Martin FE, Jacques NA, Hunter N. Determination of bacterial load by real-time PCR using a broad-range (universal) probe and primer set. Microbiology 2002; 148: 257-66.

[20] Nonnenmacher C, Dalpke A, Rochon J, Flores-de-Jacoby L, Mutters R, Heeg K. Real-time polymerase chain reaction for detection and quantification of bacteria in periodontal patients. J Periodontol 2005; 76: 1542-49.

[21] Socransky SS, Smith C, Haffajee AD. Subgingival microbial profiles in refractory periodontal disease. J Clin Periodontol 2002; 29: 260-8.

[22] Yano A, Kaneko N, Ida H, Yamaguchi T, Hanada N. Real-time PCR for quantification of Streptococcus mutans. FEMS Microbiol Lett 2002; 217: 23-30.

[23] Yoshida A, Suzuki N, Nakano Y, Oho T, Kawada M, Koga T. Development of a 5' fluorogenic nuclease-based real-time PCR assay for quantitative detection of Actinobacillus actinomycetemcomitans and Porphyromonas gingivalis. J Clin Microbiol 2003; 41: 863-6.

[24] Dibart S, Skobe Z, Snapp KR, Socransky SS, Smith C, Kent R. Identification of bacterial species on or in crevicular epithelial cells from healthy and periodontally diseases patients using DNA-DNA hybridization. Oral Microbiol Immunol 1998; 113: 30-5.

[25] Sanz, M, Lau L, Herrera D, Morillo JM, Silva A. Methods of detection of Actinobacillus actinomycetemcomitans, Porphyromonas gingivalis and Tannerella forsythensis in periodontal microbiology, with special emphasis on advanced molecular techniques: a review. J Clin Microbiol 2004; 31: 1034-47.
[26] Martin FE, Nadkarni MA, Jacques NA, Hunter N. Quantitative microbiological study of human carious dentine by culture and real-time PCR: association of anaerobes with histopathological changes in chronic pulpitis. J Clin Microbiol 2002; 40: 1698-704.

[27] Blakemore RP, Canale-Parola E. Arginine catabolism by Treponema denticola. J Bacteriol 1976; 128(2): 616-22.

[28] Broberg, EK, Nygardas M, Salmi AA, Hukkanen V. Low copy number detection of herpes simplex virus type $1 \mathrm{mRNA}$ and mouse Th1 type cytokine mRNAs by lightCycler quantitative real-time PCR. J Virol Methods 2003; 112: 53-65.

[29] Fey A, Eichler S, Flavier S, Christen R, Hofle M, Guzman A. Establishment of real-time PCR-based approach for accurate quantification of bacterial RNA targets in water, using Salmonella as a model organism. Appl Environ Microbiol 2004; 70(6): 3618-23.

[30] Baumgartner JC, Watkins BJ, Bae KS, Xia T. Association of blackpigmented bacteria with endodontic infections. J Endod 1999; 25: 413-5.

[31] Conrads G, Gharbia SE, Gulabivala K, Lampert F, Shah HN. The use of $16 \mathrm{~S}$ rDNA directed PCR for the detection of endodontopathogenic bacteria. J Endod 1997; 23: 433-38.

[32] Goncharoff P, Figurski DH, Stevens RH, Fine DH. Identification of Actinobacillus actinomycetemcomitans: Polymerase chain reaction amplification of $L k t A$-specific sequences. Oral Microbiol Immunol 1993; 8: 105-10

[33] Maeda H, Fujimoto C, Haruki Y, Maeda T, Kokeguchi S, Petelin M, Arai H, Tanimoto I, Nishimura F, Takashiba S. Quantitative real-time PCR using TaqMan and SYBR Green for Actinobacillus actinomycetemcomitans, Porphyromonas gingivalis and Prevotella intermedia, tetQ gene and total bacteria. FEMS Immunol Med Microbiol 2003; 39: 81-6

[34] Kuboniwa M, Amano A, Kimura KR, Sekine S, Kato S, Yamamoto Y, Okahashi N, Iida T, Shizukuishi S. Quantitative detection of periodontal pathogens using real-time polymerase chain reaction with TaqMan probes. Oral Microbiol Immunol 2004; 19: 168-76.

[35] Heid CA, Stevens J, Livak KJ, Williams M. Real time quantitative PCR. Genome Res 1996; 6: 986-94.

[36] Betzl G, Seller M, Eichner C, Kalbe A, Geyer, M, Kleider W. Miltenburg R. Reproducibility of PCR on the LightCycler system. Biochemica 2000; 1: 22-6

[37] Socransky SS, Haffajee AD. Periodontal microbial ecology. Periodontol 2005; 38: 135-87.

Received: November 29, 2007

Accepted: February 4, 2008

(C) Kirakodu et al.; Licensee Bentham Open.

This is an open access article licensed under the terms of the Creative Commons Attribution Non-Commercial License (http://creativecommons.org/licenses/ by-nc/3.0/) which permits unrestricted, non-commercial use, distribution and reproduction in any medium, provided the work is properly cited. 